Baltic Astronomy, vol. 6, 71, 1997.

\title{
ARCHAEOASTRONOMY: THE NEWPORT TOWER
}

\author{
William Penhallow
}

Quonochotaug Observatory, Charleston, Rhode Island 02813

Received May 30, 1996

ABSTRACT. The Newport Tower is a masonry structure of fieldstone about 28 feet high and 22 feet in diameter located near the top of a hill overlooking the harbor in Newport, Rhode Island. In essence it is a cylinder with Romanesque arches resting on eight pillars. The cylinder has three major openings as well as four smaller ones. On the inside there are eight indentations for beams on a first floor and four for a second,.In addition there are seven niches and a fireplace on the inside. A careful photogrammetric survey of the tower done by the Technical University of Denmark for the Danish National Museum provided data for the calculation of declinations, azimuths and altitudes associated with possible pairs of features. Numerous alignments involving the Sun and Moon indicate an emphasis on determining the location of the nodes of the Moon's orbit. Accurate determination of true north by observing Polaris at upper culmination is evident. Possible observations of Sirius are indicated. These results provide strong evidence that astronomy was involved in the design and use of this intriguing structure first mentioned in Governor Arnold's will in 1677. Further study is clearly warranted.

This paper was published in the New England Antiquities Research Association Journal, p. 44, 1994

Key Words: history of astronomy 
